form of a hard, dry, and rough coating like emery paper, and the friction in the bore is increased to a very large extent." Thus it may readily be seen that under varying circumstances the requisite conditions are very likely to occur, and experiments should most undoubtedly be undertaken to test the validity of this source of accident, and we think that great credit is due to Sir William Palliser for having been the first to point it out. Yet another cause has been insisted on as likely to bring about the destruction of some of our Woolwich rifled guns. In a paper read by Prof. Osborne Reynolds at the meeting of the British Association at Bradford, it was shown that the system of rifling employed at Woolwich, giving a gradually increasing twist to the grooves, threw a much greater strain on the gun than a uniform twist, and rendered it impossible for the studs on the shot to fit the grooves with accuracy throughout the whole length of the bore. The objections raised by Prof. Reynolds have, we believe, remained unanswered and perhaps unnoticed now for five or six years by the departmental officers, and during this time many bundreds of guns have been constructed on the condemned principle. Now that so much public attention is being directed to the whole system of gun manufacture as carried on at Woolwich, and the criticisms adverse to its merits are so numerous it would be well that the country should have further assurance that the system is founded on a safe scientific basis, or that the errors, if they exist, should be admitted and rectified.

It is admitted that with the increasing twist in the rifling the shearing of the studs has frequently shown that the projectile has some difficulty in centring itself in the bore while the great wear in the steel tubes of the guns occasionally used for practice on board ship points to a short life for the gun, but we are not aware that the destruction of a gun has hitherto been traced with certainty to the jamming of the studs between two grooves. In the event of this occurring it is shown conclusively by Mr. Longridge, in a letter inserted in Engineering last week, that the strain would be far more than sufficient to burst the gun. The bursting pressure of the gases would easily split the tube and coils, or the energy of the shot if only moving with a moderate velocity would cause a longitudinal stress which the steel tube would be quite unable to resist.

It may appear to some useless to draw particular attention to the various causes of this terrible accident that have been suggested now that the report of the Committee has been made known and has shown that all the suppositions are equally erroneous, but in our opinion it is of the utmost importance that these dangers to which we direct attention and which might at any time cause a similar accident, should not be passed over and forgotten.

\section{CAPTAIN COOK}

$\Upsilon \mathrm{T}$ seems on first thoughts rather a strange proceeding 1 to publicly celebrate the centenary of the death of a great man, especially when that death was a murder. But this is what the Paris Geographical Society have arranged to do to-morrow in the case, not of any of their own explorers or navigators, but in the case of England's greatest exploring navigator, Captain James Cook, who was murdered roo years ago to-morrow by the natives of the Sandwich Islands. But we know that the generousminded Frenchmen do not intend to rejoice at the death of this great man, as they would do were it his birth they intended to commemorate. Cook, they know, was one of the greatest of geographical explorers, and it is quite natural and commendable that the Society, in their enthusiasm for their science and its promoters, should wish in some way to show their reverence for a man like Cook on the centenary of his remarkable death. Cook, and with him England, owed some gratitude to the French, whose government of the time, though at war with this country, generously gave instructions to their war-ships and colonial governors, not only not to molest Cook in his pursuit of knowledge, but to render him all reasonable assistance. It is obvious that only about every third generation can take part in celebrating the centenary of a man's birth, and it is natural, therefore, that those of the intermediate generation who count him among their beroes, should take advantage of the occurrence of the centenary of his death to show their appreciation of his greatness. In Cook's case birthday and death-day were only about half a century apart, the date of the former being October 27, 1728 .

Why our own Geographical Society should have left it to our French neighbours to commemorate so remarkable an event in the history of geographical discovery, we cannot undertake to say, though it seems to savour somewhat of dog-in-the-manger that they have declined the invitation to send an official representative. It would surely have been easy for them to have organised some kind of demonstration that would both have honoured the memory of one of our greatest naval heroes and most scientific of navigators, and at the same time have proved both interesting and instructive to the public. However, England will not be entirely unrepresented tomorrow, as we understand the Admiralty are contributing several original charts to the exbibition of the Paris Society. Mr. Brassey, who has visited the spot where Cook was killed, has sent to the Society a number of views and documents to be exhibited. $\mathrm{Mr}$. Jackson has also promised to send valuable maps and manuscripts from Cook's own hand. Researches will be executed in the Archives to discover the original of the Ordre du Roi, forbidding French cruisers to molest Captain Cook's expedition, and in spite of the declaration of war, to assist him if necessary for the fulfilling of a mission interesting the whole of mankind.

We need not recount the claims of Captain Cook to be regarded as one of the greatest, as he was one of the most scientific, of navigating explorers; probably there are few of our readers who have not at one time or other read some account of the voyages of Captain Cook. The son of a peasant, he rose to his honourable position by sheer force of genius and its invariable accompaniment, hard work. To him we owe the discovery of the Sand wich, and many other Pacific Islands. His enthusiasm on behalf of science was manifested in his work at Tahiti in connection with the memorable transit of Venus of June 3, 1769. He gave certainty to our knowledge of New Zealand, and left not much to be done to fill up with accuracy an outline of the coast of Australia. He proved 
that that continent was unconnected with New Guinea, and above all, dispelled the long-lived illusion of a great southern continent, baving been the first to cross the Antarctic Circle. At high south latitudes he sailed nearly all round the confines of the Antarctic, adding greatly to a knowledge of the geography of this unknown region, and proving once for all, as we have said, that a "great southern continent" was a delusion, at least outside the Antarctic Circle. A comparison of the maps of 1762 and 1785 will serve to show how much was accomplished by Cook in this direction. In his second voyage of three years, 1772-75, Cook sailed over 20,000 leagues in the Pacific and Southern Oceans. And it was not only geographical knowledge that was thus advanced by his skill and determination. He was always accompanied by a staff of scientific specialists, to whom he gave every opportunity of pursuing research in their own departments, and thus of adding enormously to a knowledge of the natural history (in its widest sense) of great tracts of our globe. In the Transit expedition, for example, he was accompanied by the young Joseph Banks as naturalist. His third, and fatal voyage, was undertaken mainly for the discovery of a North-West Passage, Cook and Capt. Clarke sailing in the Resolution and Discovery from Plymouth in July, 1776 , and after a roundabout voyage by the South Pacific, the Sandwich Islands were discovered on January 18,1778 . After attempting to penetrate the Arctic Ocean, he was compelled to turn back, and resolved to spend the winter in completing the survey of the Sandwich Islands. Here, as almost everywhere else that he went, Cook won the bearts of the natives by his gentle, firm, and perfectly upright dealing, in this respect being a pattern to all explorers. The end is too well known, and we need not repeat the details of the sad event which happened at Karakakooa Bay, on the south side of Hawaii, on February I4, 1779. No blame can be attributed to Cook, and, probably, very little to the natives themselves. Had the lieutenant who accompanied Cook on shore, and the sailors themselves, possessed a little of his tact and true bravery the catastrophe might have been prevented. There is reason to believe that the islanders regarded Cook as a sort of superior being, a kind of beaven-sent messenger whom they halfexpected, and that they actually worshipped him as a god. Indeed it has been said that it was only when the first stunning blow from a club proved him human that their chagrin and disappointment vented themselves in barbarous massacre. There seems no doubt that the natives were sincerely sorry for what had occurred, and continued to worship his memory, if not his bones, for long after. It is commonly stated that his remains were obtained and buried in the sea, but we would refer our readers to a remarkable story published in NATURE, vol. viii. p. 2Ir. From this it would seem that the large bones of Cook's body had been retained by the islanders, and tended and enshrined as those of a hero, if not of a deity. Whatever amount of truth there may be in the details of this story, it, along with other evidence, tends to prove that the catastrophe was a sad mistake, regretted by none more than the natives themselves.

Cook's instincts were thoroughly scientific, and he did all that his circumstances would admit of to qualify himself to carry on his great and important work on the basis of scientific principles. The results show that all things considered science profited largely by his labours, and that to-morrow a foreign society will strive to keep green the memory of one of England's most scientific navigators, one of her ablest and most lovable sons.

\section{THE SAMOAN LANGUAGE}

A Grammar and Dictionary of the Samoan Innguage. By the Rev. George Pratt. Second Edition. Edited by the Rev. S. J. Whitmee, F.R.G.S. (Trübner and Co., I878.)

THIS is perhaps as complete a guide to the study of the Samoan language as could be expected under the circumstances. It consists, properly, of four parts : a grammar, which, for obvious reasons, is necessarily disappointing; a chapter on the native poetry, which would be much more useful were the specimens given accompanied by a translation, or at least by more copious notes; an English-Samoan vocabulary of about 4,500 fairly well-selected words, and a Samoan-English dictionary of more than double that number of terms. The editor informs us that many of the names of the indigenous flora and fauna collected by him still remain to be published. They will doubtless be embodied in the large "Comparative Polynesian Dictionary" he is now preparing, and when this is done we shall bave at last a well-nigh complete dictionary of the most typical of the eastern Polynesian languages.

The grammatical portion of the work, notwithstanding the many extremely useful and suggestive additions of the editor, still leaves so much to be desired that we cannot but regret he did not re-cast this whole section, and give us a treatise more in harmony with the present. state of linguistic studies. When we read in Mr. Pratt's preface that he was led to prepare a Samoan syntax "by observing, while reading Nordheimer's Hebrew grammar, that the Samoan in many points resembled the Hebrew," we feel at once that it would be hopeless to expect from him a sound exposition of the structure of this language, and the most cursory glance fully confirms this anticipation. Hebrew is a member of the Semitic family of languages, and is consequently an inflecting tongue. Hence it can have nothing beyond mere coincidences in common with the Eastern Polynesian group, which has scarcely yet got much beyond the isolating state, of which Chinese is typical. Its position, in fact, is quite unique, and until its true character is thoroughly realised we shall never get a rational treatment of the subject. This obvious truth was largely recognised by Gaussin, which at once explains the satisfactory nature of his work. Had it been based on the Samoan instead of on the Tahitian and Marquesan dialects, the result would doubtless have been still more satisfactory, and he would have aroided some of the misconceptions which detract from the value of that treatise. Yet even so it incidentally throws more light on the real genius of the Samoan itself than does the present work. Here the treatment of the verb is especially meagre and irrational. The schemes of tense and mood occupy less than two pages, and each tense is illustrated by a different verb, pule (rule) for the present, alof $a$ (love) for the imperfect, sao (escape) for the perfect, 